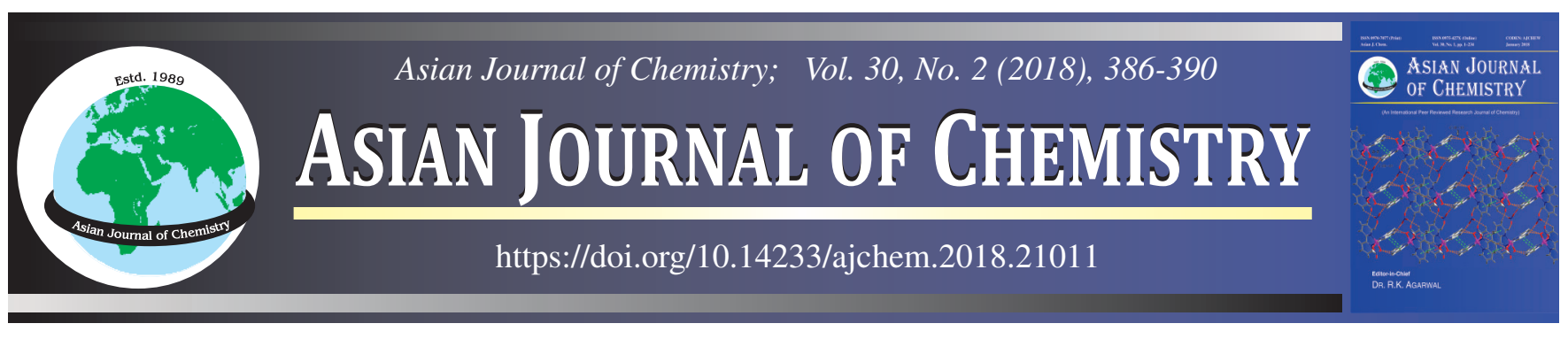

\title{
Structural, Vibrational and Physical Properties on Tetramethyammonium Cadmium Bromide Ferroelectric Single Crystal
}

\author{
N. BhUVANESWARI ${ }^{1,2, *}$ and K. VENKATACHALAM ${ }^{3}$
}

${ }^{1}$ Research and Development Center, Bharathiar University, Coimbatore-641 046, India

${ }^{2}$ Department of Physics, Hindusthan College of Engineering \& Technology (Autonomous), Coimbatore-641 032, India

${ }^{3}$ Department of Physics, Government Arts College (Autonomous), Coimbatore-641 018, India

*Corresponding author: E-mail: bhuvana23mscphd@gmail.com

Received: 28 August 2017;

Accepted: 19 October 2017;

Published online: 31 December 2017;

AJC-18711

\begin{abstract}
Ferroelectric crystals of tetramethylammonium cadmium bromide (TMACB) has been grown by slow evaporation solution growth technique at room temperature. Single crystal X-ray diffraction analysis revealed the newness of the crystal structure belonging to the hexagonal crystal system with lattice parameters $a=9.257 \AA, c=6.9167 \AA$ and $\alpha=\beta=90^{\circ}, \gamma=120^{\circ}$. The functional groups in the complex were identified using FT-IR and FT-Raman analyses. The thermal stability and decomposition details were studied through TG/DTA analyses. The grown crystal was subjected to surface morphology by SEM analysis and the optical properties was studied by UV-VIS-NIR analysis. From the photoluminescence studies, it was confirmed that the grown crystal has been green emission. The Vickers microhardness test conducted on the grown crystal suggests that the crystal has a relatively low mechanical strength. The dielectric constant and dielectric loss were calculated by varying the frequencies at room temperature. Dielectric studies of the grown crystal had been measured in the temperature range of 313 to $453 \mathrm{~K}$.
\end{abstract}

Keywords: Tetramethyl ammonium cadmium bromide, Crystals, Optical study.

\section{INTRODUCTION}

In current years, metal organic complexes have attracted good attention owing to a result of their application in second and third harmonic generation, optical bistability, laser driven fusion, laser remote sensing, optical disc data storage, medical and spectroscopic image processing, colour display and optical communication [1-3]. The metallic organic complexes combined the benefits of each the organic and inorganic substances. Many new materials are having a wide application inside the area of frequency conversion [4]. Typically these compounds are fashioned through weak hydrogen and van der Waals bonds. However, the use of some organic crystals are substantially restrained to high power laser packages because of their demerits such as low laser harm threshold, negative mechanical, low thermal balance and difficulty in producing big sized crystals. To conquer the above said negative aspects, an alternative magnificence of fabric which combines both the fine elements of organic and inorganic referred to as metal organic has been advanced [5]. This type of metal organic compounds containing organic molecules are connected to metal atoms by way of carbon-metal bonds [6-8]. These sorts of substances had been used in optical switches and other photonic devices and have numerous advantages such as low cost, low dielectric steady and amazing diversity of feasible organic templates [9-11]. The organic and metal organic non-linear optical materials are attracting considerable interest because of the important potential applications in electro-optical modulator, memory, optical switches and other photonic devices [12-14]. However, they have been absolutely few reports on devices based on but, there had been unaccompanied a few reviews on gadgets primarily based on organometallics, metallic-organic and metal coordination complexes. During this period, they have been readily studied guerdon to their architectural plenty of rope and systematize of animate combinations of champion metal and ligand [15]. A large number of literature survey deals with tetramethylammonium cadmium chloride (TMACB). We rearrange halogen atoms of bromide in this structure. In preliminary X-rays diffraction study of TMACB, the space group of the crystal at room temperature $\left[\mathrm{P}_{3} / \mathrm{m}(\mathrm{z}=2)\right]$ and low temperature $\left[\mathrm{P} 6_{1}-\mathrm{P} 6_{5}(\mathrm{z}=6)\right]$ phases have been established [16]. Previous literature survey gives the ferroelectric phase transition of $\left[\left(\mathrm{CH}_{3}\right)_{4} \mathrm{~N}\right] \mathrm{CdBr}_{3}$ which denotes the complete structure of TMACB [17]. The present paper deals with preliminary study of XRD, morphology, UV-visible, FTIR, SEM, dielectrics, photoluminescence and microhardness studies. 
In the present investigation, the growth of tetramethylammonium cadmium bromide crystal and the morphology study is reported. The vibrational, thermal, mechanical, dielectric and optical properties are also discussed.

\section{EXPERIMENTAL}

Single crystal XRD analysis and morphology of the grown crystal were carried out using Enrof NORNIUS cad $4 \mathrm{X}$ ray diffractometer to determine the lattice parameter values and the structure of crystal. The sample was crushed in powder form. The intensity data were analyzed by continuous scan in $2 \theta /$ model from $10^{\circ}$ to $70^{\circ}$ in the scanning speed of $0.01 \%$. The surface study of the grown crystals by scanning electron microscope using a JEOL Model JSM-6390LV. The optical absorption spectra were recorded using Varian, Cary 5000 UV-VIS spectrometer. The FTIR and FT Raman spectra were recorded to confirm the presence of functional groups by using Bruker: RFS 27 spectrometer in the frequency range 4000 to $500 \mathrm{~cm}^{-1}$. The Vickers microhardness was used to calculate the variation of hardness with respect to the indented load for a fixed time of $10 \mathrm{~s}$. The photoluminescence spectrum was recorded using JOBIN YVON FLUROLOG-3-11 spectroflurometer at room temperature. Dielectric study was carried out using the impedance analyzer (HIOKI LCR HITESTER $3532-50$ ) in the frequency range $42 \mathrm{~Hz}-1 \mathrm{MHz}$ at varies temperatures between RT- $145^{\circ} \mathrm{C}$.

Crystal growth: The organic metal of tetramethylammonium cadmium bromide was synthesized by slow evaporation method at room temperature. The aqueous solution of tetramethylammonium and cadmium bromide was taken in the ratio of $2: 1$. In the chemical reaction, the two salts are mixed with $20 \mathrm{~mL}$ deionized water, the mixed solution was stirred at $3 \mathrm{~h}$ using magnetic stirrer. The prepared solution was covered using butter sheet and kept at free of mechanical disturbance and dust for a period of 10 days. The colourless, transparent and good quality crystal was grown. In the purification process, the grown crystal was mixed again with $20 \mathrm{~mL}$ water and stirred at $3 \mathrm{~h}$. The prepared solution was filtered and kept in an undisturbed place. Good quality crystals were harvested after a period of 17 days. The photographs of as-grown crystals of tetramethylammonium cadmium bromide are shown in Fig. 1.

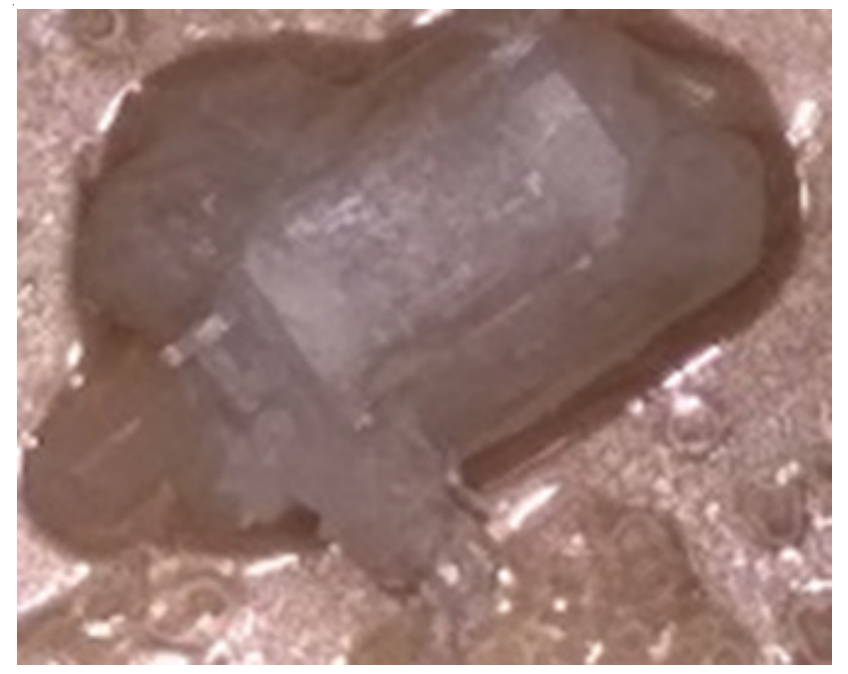

Fig. 1. Crystal photo of TMACB

\section{RESULTS AND DISCUSSION}

The single crystal XRD analysis had been carried out to confirm the structure of the grown crystal. The lattice parameter values were found to be $\mathrm{a}=9.257 \AA, \mathrm{c}=6.9167 \AA$ and $\alpha=\beta$ $=90^{\circ}, \gamma=120^{\circ}$. Using the parameter values, it is confirmed that the structure of grown crystal was hexagonal closed packed structure. The space group was $\mathrm{P}_{3} / \mathrm{m}(\mathrm{z}=2)$. The experimental values are in good agreement with the reported literature [16,17]. The morphology of the grown crystal is shown in Fig. 2. The prominent planes are $(11 \overline{1}),(\overline{111}),(\overline{110}),(001),(110)$ and (110). The planes $(\overline{110})$ are well developed and have dominated crystal morphology. The crystals grew faster along at $\mathrm{pH}$ value 7 [18]. The quality of grown crystal TMACB can be observed by the surface morphology of the crystal [19]. The recorded SEM analysis is shown in Fig. 3 and confirms the formation the inclusions and pits on the surface of the crystal. The particle arrangement distribution was taken $500 \times, 1500 \times, 3500 \times$ and $7000 \times$ magnification with $15 \mathrm{KV}$ acceleration voltages.

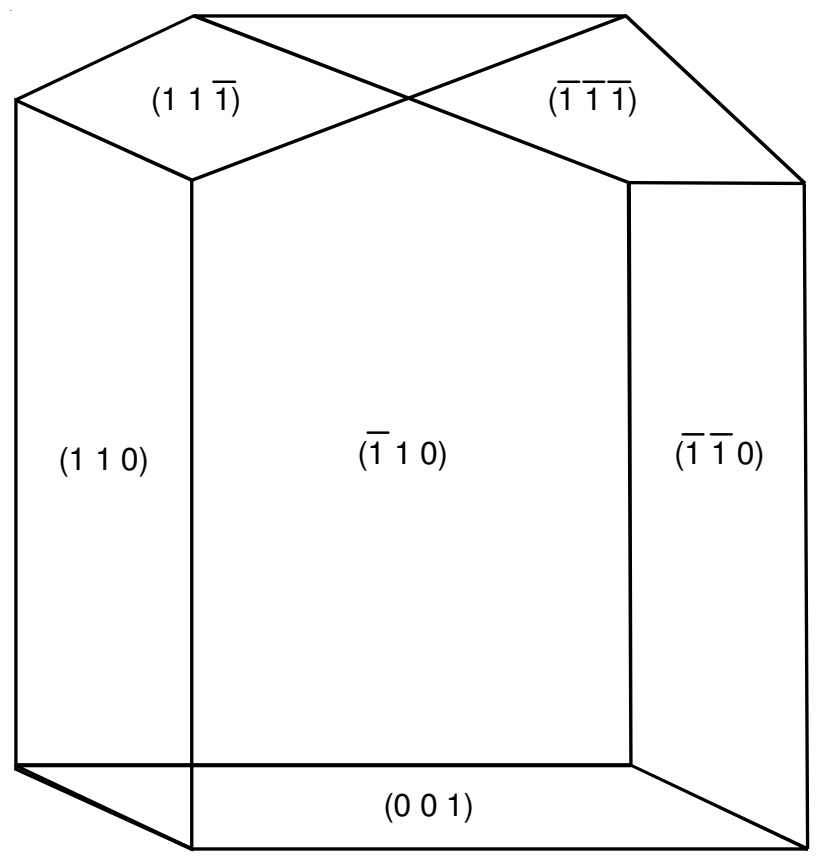

Fig. 2. Morphology of TMACB crystal

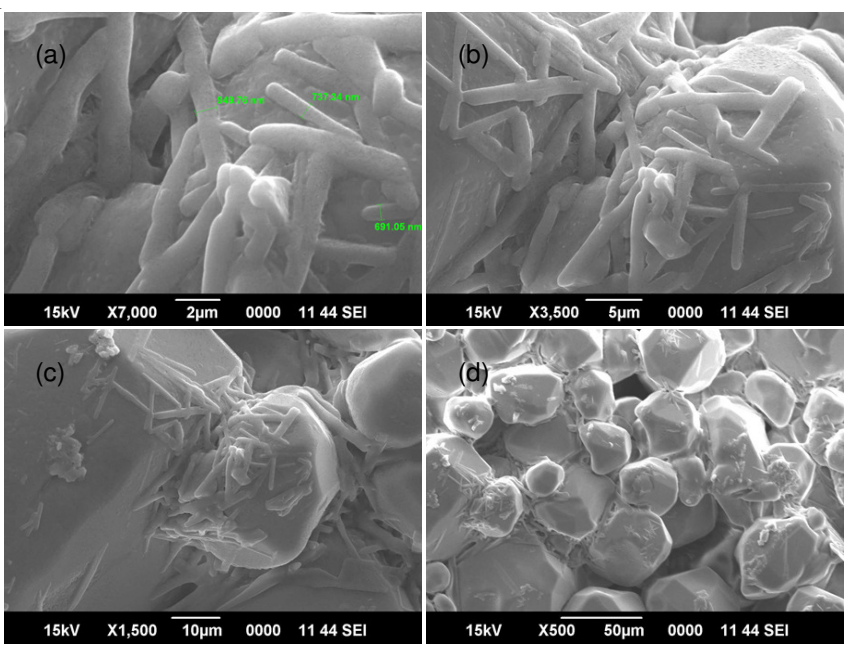

Fig. 3. SEM analysis of TMACB crystal 
Optical absorbance study: Optical absorbance and transmittance spectrum was recorded in the range of 200 to $1200 \mathrm{~nm}$. The important properties of non-linear optical crystals are good optical transmittance and lower UV cut off wavelength. The lower cut off wave length is $360 \mathrm{~nm}$. The maximum transmittance is above $90 \%$ shown in Fig. 4 . The crystal has good transparency in the range of 320 to $1100 \mathrm{~nm}$, which indicate that this crystal can be employed in the NLO application in the entire visible and IR region [20].

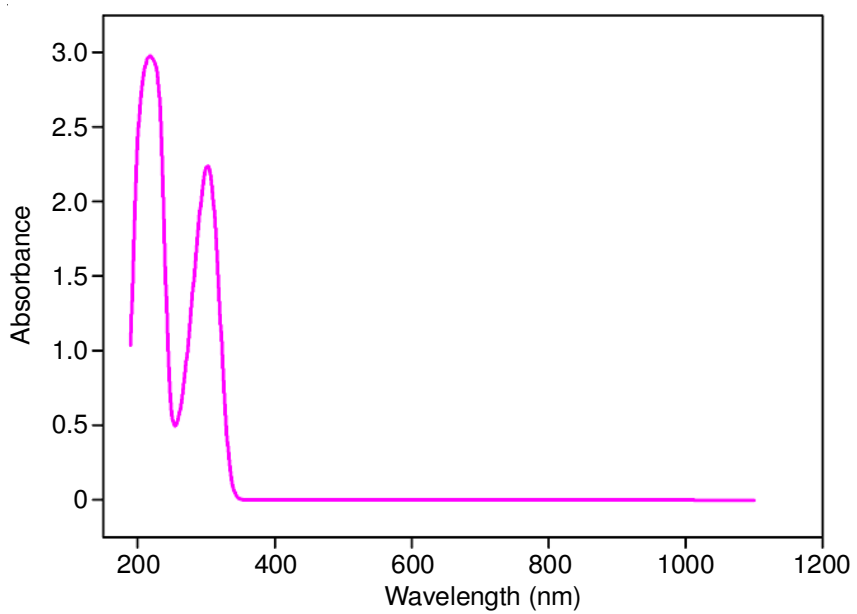

Fig. 4. UV absorbance spectrum of TMACB crystal

Vibrational analysis: FT-IR and FT-Raman spectrum of grown crystal are used to identify the functional groups present and to determine the molecular structure of the synthesized compound. The peak corresponds to the range 4000- $500 \mathrm{~cm}^{-1}$ and 4000 to $400 \mathrm{~cm}^{-1}$, respectively. The peak at 3025.53 and $3024.65 \mathrm{~cm}^{-1}$ in IR and Raman spectrum are due to the O-H stretching vibration of water molecule. The peak at 2587.68 $\mathrm{cm}^{-1}$ in FTIR is due to S-H stretching vibration (Figs. 5 and 6). The medium C-H bending mode appears at 1479.40 and 1445.49 $\mathrm{cm}^{-1}$ in FTIR and FT Raman spectrum. The peak at $1076.28 \mathrm{~cm}^{-1}$ FT IR denotes the strong C-O stretching vibration mode. The strong $\mathrm{C}=\mathrm{C}$ bending vibration is assigned at $948.98 \mathrm{~cm}^{-1}$ in FTIR and the corresponding mode appears at $947.95 \mathrm{~cm}^{-1}$ in FT-Raman. The peak value revealed at 754.17 and $751.47 \mathrm{~cm}^{-1}$ denote the medium $\mathrm{C}=\mathrm{C}$ bending mode in IR and Raman spectrum, respectively. The strong $\mathrm{C}-\mathrm{Br}$ stretching halo compound occurs at $628.79 \mathrm{~cm}^{-1}$ in FTIR spectrum.

Mechanical property: The strength of the materials for device fabrications explicitly dependent on important parameters called hardness. The Vickers's microharness test is the principal type of hardness test in which a square pyramid of diamond with apex angle equal to $136^{\circ}$ is impressed into crystal surface. The elastic deformation is equal to the strain of the given material, and its conserved in the form of elastic strain energy where the energy dissipated as heat or generated the internal defects in the material [21]. The indentation hardness of the grown crystal was measured as the ratio of applied load to the surface area of the indentation. The constant time indentation $3 \mathrm{~s}$ was maintained. Vickers's microharness number was found by using the relation:

$$
\mathrm{H}_{\mathrm{v}}=1.8544 \mathrm{P} / \mathrm{d}^{2}\left(\mathrm{Kg} / \mathrm{mm}^{2}\right)
$$

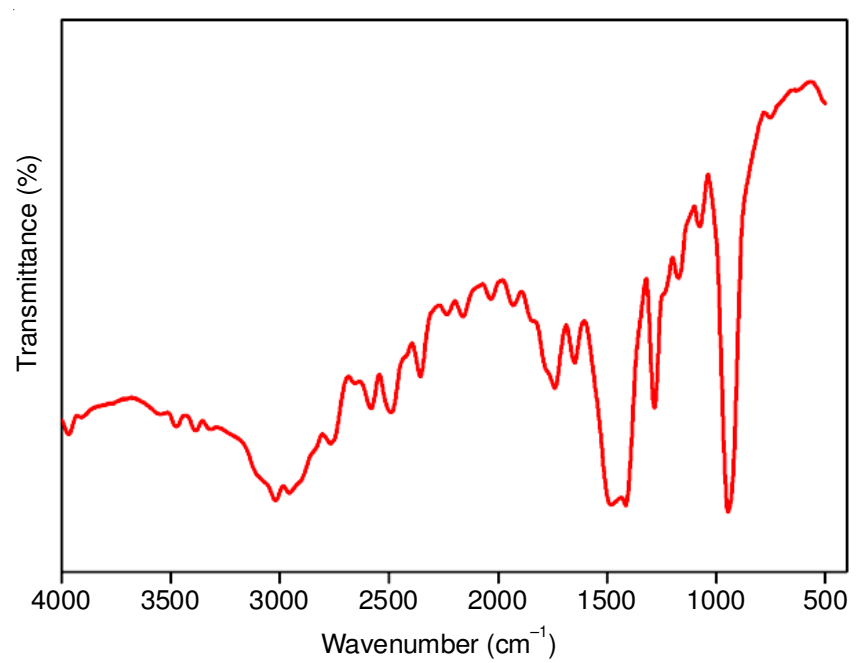

Fig. 5. FTIR spectrum of TMACB crystal

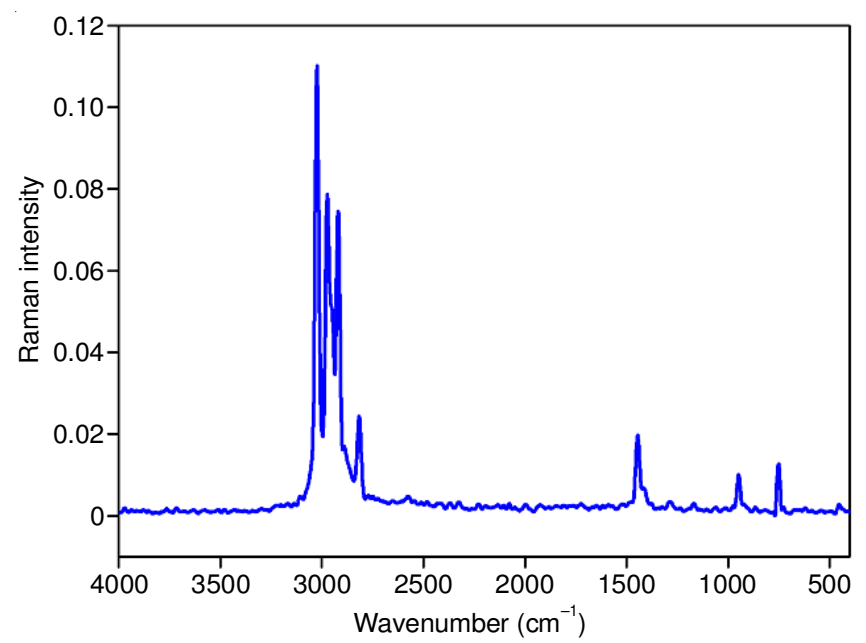

Fig. 6. FT-Raman spectrum of TMACB crystal

where $\mathrm{P}$ is the applied load in $\mathrm{Kg}$ and $\mathrm{d}$ is the mean diagonal length of the indenter impression in millimetre. It is observed that by increasing the load, there is an increase in hardness number (Fig. 7). This phenomenon is known as reverse indentation size effect [22]. The slope of the graph gives Mayer's index (n) and it is calculated to be 2.32. Mayer's index value comes out to be 1 to 1.6 for hard materials and greater than 1.6 for soft materials [23,24]. For that reason, tetramethylammonium cadmium bromide crystal belongs to soft material category.

Dielectrics constant and dielectric loss: The temperature dependent dielectric constant $\left(\varepsilon^{\prime}\right)$ for the grown crystal shows that the dielectric constant $\left(\varepsilon^{\prime}\right)$ initially increases up to $433 \mathrm{~K}$. This indicates that the grown crystals begin to undergo phase transition from paraelectric to ferroelectric at this temperature, which is called as Curie temperature $\left(\mathrm{T}_{\mathrm{C}}\right)$. Thus, the peak at $433 \mathrm{~K}$ indicates the ferroelectric phase transition for various frequencies.

It is observed that the dielectric constant and dielectric loss decreases exponentially with increasing frequency and then attains almost a constant value in the high frequency region [25-28]. The low value of dielectric constant at higher frequencies is important for the fabrication of ferroelectric devices. It is also observed that as the temperature increases, the value 


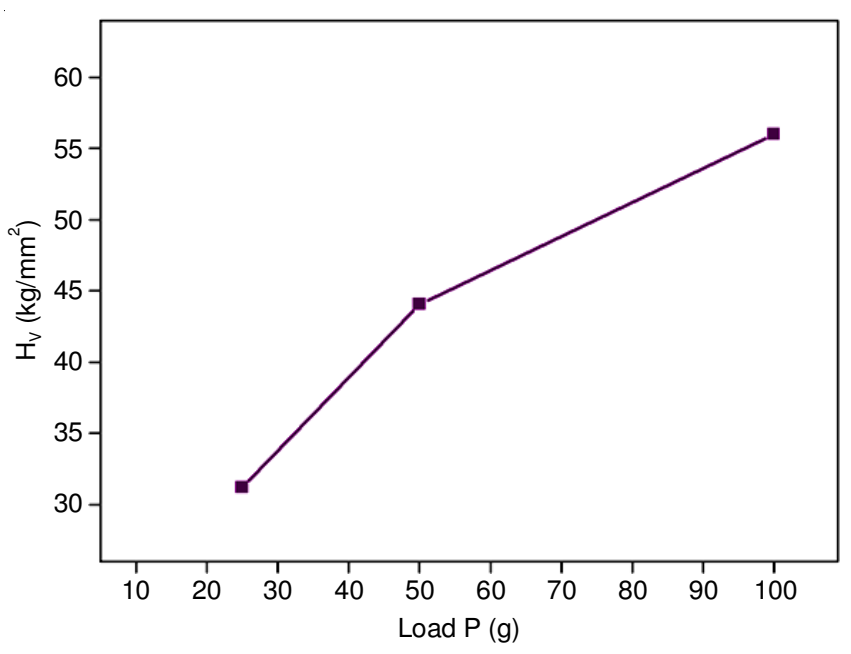

Fig. 7(a). Hardness number $\left(\mathrm{H}_{\mathrm{V}}\right)$ vs. load $(\mathrm{P})$ for TMACB

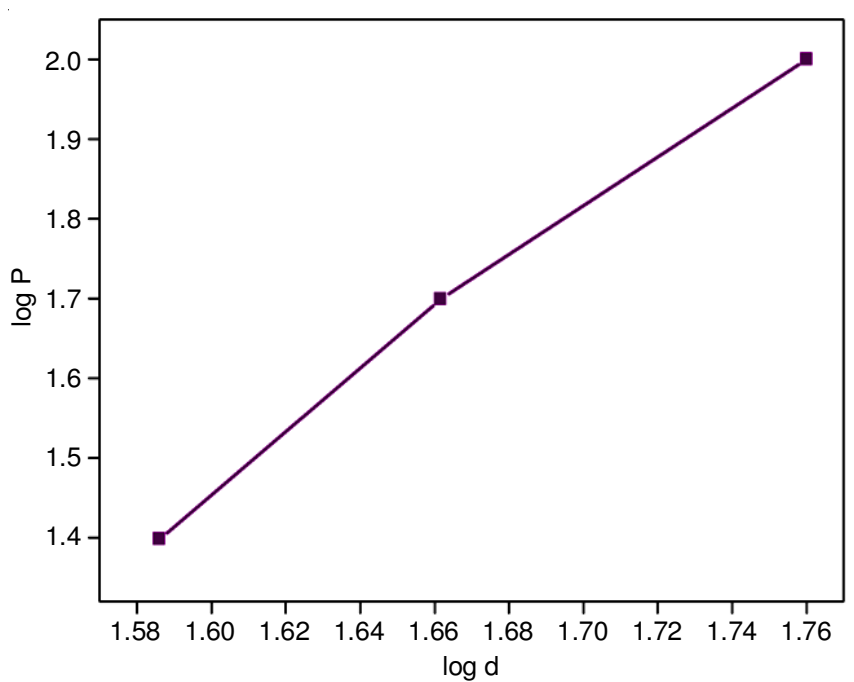

Fig. 7(b). $\log \mathrm{P} v s . \log \mathrm{d}$ for TMACB

of the dielectric constant also increases. Fig. 8 observed the increment of dielectric constant and dielectric loss may due to interfacial polarization behaviour.

Photoluminous study: The photoluminous studies are prepared rather than optical absorption to detect the lower concentration of defects. This is a mechanism where the impurity on absorption of light gives rise to ground state to exited state. photoluminescence emission spectrum (Fig. 9) was recorded in the range of 300 to $700 \mathrm{~nm}$ at room temperature. The emission peak observed at $569.8 \mathrm{~nm}$ indicates the presence of intrinsic defects in the forbidden band region for this TMACB crystal. The origin of green band can be attributed to the relaxation of polarization defects $[29,30]$.

\section{Conclusion}

Single crystal of tetramethylammonium cadmium bromide (TMACB) was grown from aqueous solution by the slow evaporation method at room temperature. From the single crystal Xray diffraction analysis, it is observed that TMACB crystallized in hexagonal crystal system with $\mathrm{P}_{3} / \mathrm{m}$ space group . The lattice parameter values are presented .The morphology of the grown crystal were analyzed. FTIR and FT-Raman spectral studies revealed the presence of functional group. The lower cut off
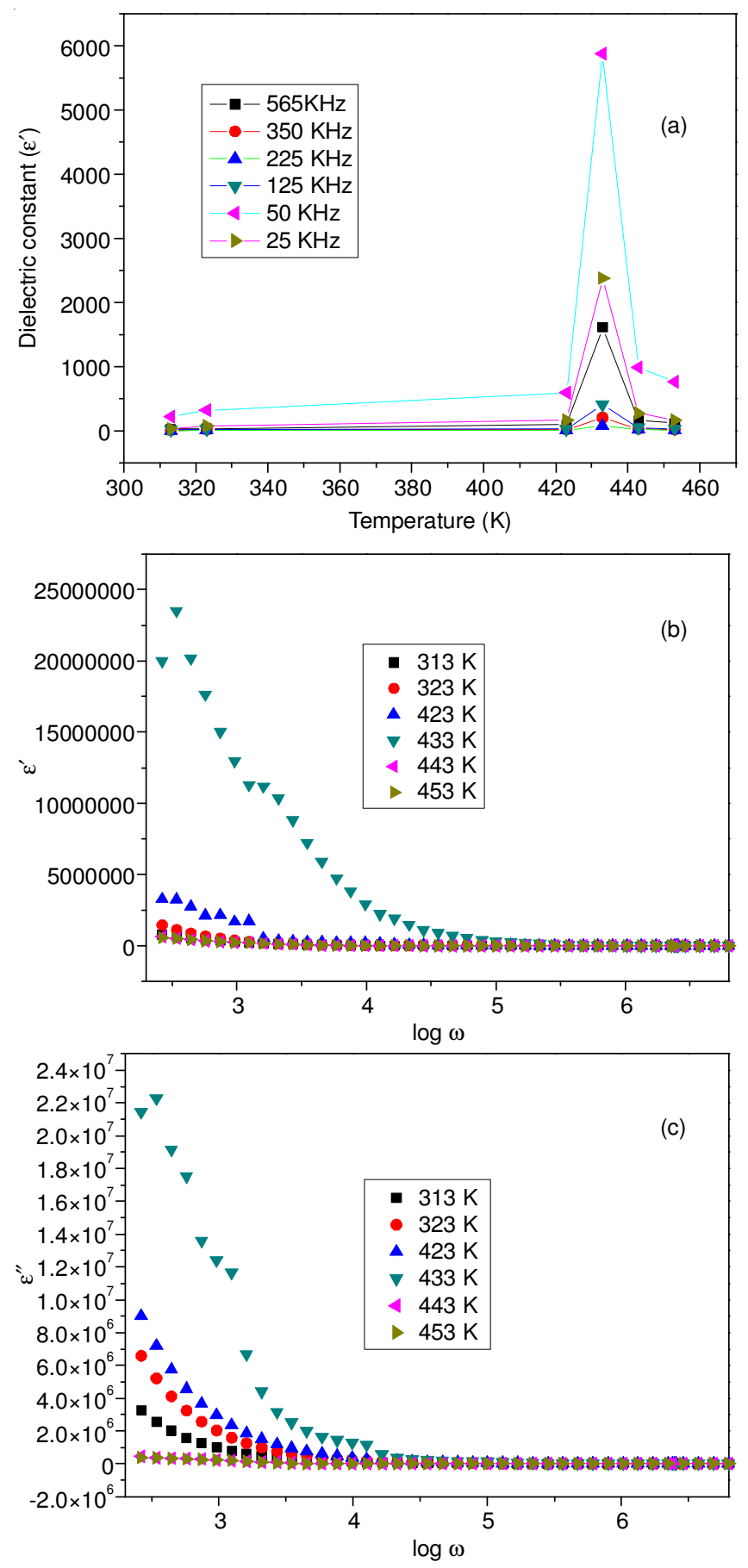

Fig. 8. Dielectric analysis of TMACB crystal

wavelength was found to be $360 \mathrm{~nm}$. The quality of the grown crystal was measured by SEM analysis. Photoluminescence spectral studies give the information about strong charge transfer in the molecules. Vickers microhardness studies carried out for the grown crystal and observed that the hardness value increases with increasing the load and at last cracks occur. Thus the results show that TMACB crystal belongs to soft material category. The dielectric studies carried out to know the variation of dielectric constant and dielectric loss with frequency at different temperature. This indicates that the grown TMACB crystals begin to undergo phase transition from paraelectric to ferroelectric at $433 \mathrm{~K}$. Thus, the peaks indicates the ferroelectric phase transition for various frequencies. 


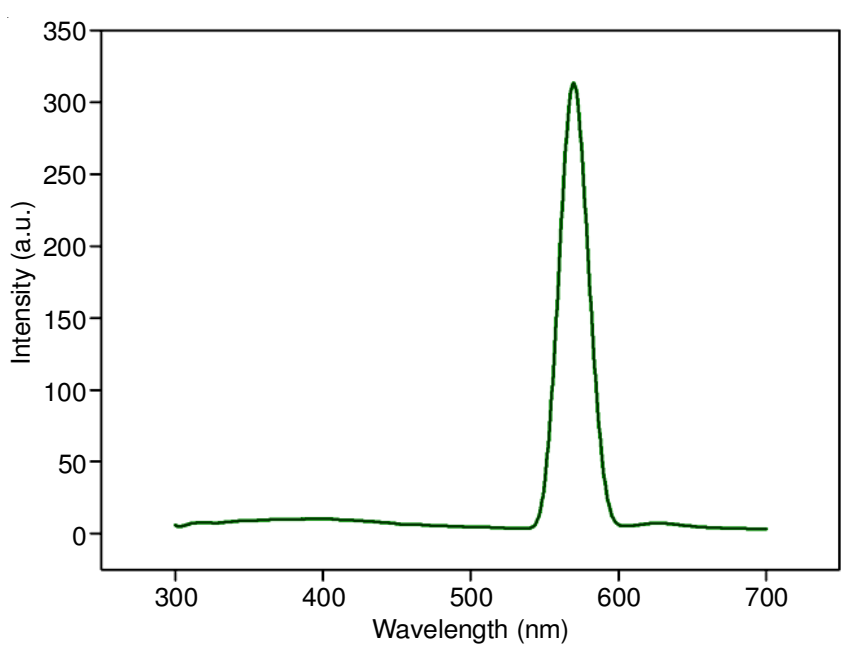

Fig. 9. Emission spectrum of TMACB

\section{REFERENCES}

1. R. Rajasekaran, P.M. Ushasree, R. Jayavel and P. Ramasamy, J. Cryst. Growth, 229, 563 (2001); https://doi.org/10.1016/S0022-0248(01)01229-5.

2. R. Rajasekaran, R.M. Kumar, R. Jayavel and P. Ramasamy, J. Cryst. Growth, 252, 317 (2003); https://doi.org/10.1016/S0022-0248(02)02467-3.

3. S. Bhattacharya, P. Dastidar and T.N. Guru Row, Chem. Mater., 6, 531 (1994);

https://doi.org/10.1021/cm00040a031.

4. L. Shivachev, K. Kossev, L.T. Dimowa, G. Yankov, T. Petrov, R.P. Nikolova and N. Petrova, J. Cryst. Growth, 376, 41 (2013); https://doi.org/10.1016/j.jcrysgro.2013.04.040.

5. Y. Liu, F. Yu, Z. Wang, S. Hou, L. Yang, X. Xu and X. Zhao, CrystEngComm, 16, 7141 (2014) https://doi.org/10.1039/C4CE00869C.

6. D. Isakov, E. de Matos Gomes, M.S. Belsley, V.H. Rodrigues and M.M. Ramalho Costa, CrystEngComm, 14, 3767 (2012); https://doi.org/10.1039/c2ce06652a.

7. 7 S. Adhikari, S.K. Seth and T. Kar, CrystEngComm, 15, 7372 (2013); https://doi.org/10.1039/c3ce41079j.

8. S. Brahadeeswaran, V. Venkataramanan, J.N. Sherwood and H.L. Bhat, J. Mater. Chem., 8, 613 (1998); https://doi.org/10.1039/a705138g.

9. S. Mendiratta, C.-H. Lee, M. Usman and K.-L. Lu, Sci. Technol. Adv Mater., 16, 054204 (2015); https://doi.org/10.1088/1468-6996/16/5/054204.

10. Z. Fang, O.Y. Chen and C.Z. Zhao, Optics Laser Technol., 46, 103 (2013); https://doi.org/10.1016/j.optlastec.2012.05.041.

11. S. Bhadauria, M. Das and S. Saxena, Arch. Phys. Res., 2, 36 (2011).
12. M. Jazbinsek and P. Günter, eds.: A. Chen and E. Murphy, Organic Electro-optic Crystal Modulators, In: Broadband Optical Modulators: Science, Technology and Applications, CRC Press, Boca Raton, FL, p. 281(2011).

13. L.F. Capitán-Vallvey and A.J. Palma, Anal. Chim. Acta, 696, 27 (2011); https://doi.org/10.1016/i.aca.2011.04.005.

14. A.C. Fahrenbach, S.C. Warren, J.T. Incorvati, A.-J. Avestro, J.C. Barnes, J.F. Stoddart and B.A. Grzybowski, Adv. Mater, 25, 331 (2013); https://doi.org/10.1002/adma.201201912.

15. S. Das, A. Nag, D. Goswami and P.K. Bharadwaj, J. Am. Chem. Soc., 128, 402 (2006); https://doi.org/10.1021/ja056771q.

16. G. Aguirre-Zamalloa, M. Couzi, N.B. Chanh and B. Gallois, J. Phys. France, 51, 2135 (1990); https://doi.org/10.1051/iphys:0199000510190213500.

17. G. Aguirre-Zamalloa, G. Madariaga, M. Couzi and T. Breczewski, Acta Crysta. B, 49, 691 (1993); https://doi.org/10.1107/S010876819300182X

18. S. Devashankar, L. Mariappan, P. Sureshkumar and M. Rathnakumari, J. Cryst. Growth, 311, 4207 (2009); https://doi.org/10.1016/i.jcrysgro.2009.06.056.

19. R. Rajendran, T.H. Freeda, U.L. Kalasekar and R.N. Peruma, Adv. Mater. Phys. Chem., 1, 39 (2011); https://doi.org/10.4236/ampc.2011.12007.

20. S. Kataki, S. Hazarika and D.C. Baruah, J. Environ. Manage., 196, 201 (2017); https://doi.org/10.1016/j.jenvman.2017.02.058.

21. H. Yadav, N. Sinha and B. Kumar, Mater. Res. Bull., 64, 194 (2015); https://doi.org/10.1016/j.materresbull.2014.12.065.

22. P. Pandi, G. Peramaiyan, G. Bhagavannarayanaa, R. Mohannkumar and R. Jayavel, Optik, 124, 5792 (2013); https://doi.org/10.1016/j.ijleo.2013.04.058.

23. M. Magesh, G.A. Babu and P. Ramasamy, J. Cryst. Growth, 324, 201 (2011); https://doi.org/10.1016/j.jcrysgro.2011.03.057.

24. K. Jagannathan, S. Kalainathan and T. Gnanasekaran, Mater. Lett., 61, 4485 (2007); https://doi.org/10.1016/j.matlet.2007.02.033.

25. K.C. Kao, Electric Polarization and Relaxation, In: Dielectric Phenomena in Solids, Elsevier Academic Press, San Diego, USA (2004)

26. I.S. Zheludev, Physics of Crystalline Dielectrics, I \& II, Plenum Press, New York, London (1971).

27. N. Goel, N. Sinha and B. Kumar, Opt. Mater, 35, 479 (2013); https://doi.org/10.1016/j.optmat.2012.10.020.

28. K.A. Wishah, Y.A. Mahmud, M. Abdul-Gader, M. Al-Haj Abdallah and R.N. Ahmad-Bitar, Appl. Phys., A Mater. Sci. Process., 43, 61 (1987); https://doi.org/10.1007/BF00615207.

29. S.J. Joshi, B.B. Parekh, K.D. Vohra and M.J. Joshi, Bull. Mater. Sci., 29, 307 (2006); https://doi.org/10.1007/BF02706501.

30. S.S. Kirupavathy, S.S. Mary, P. Srinivasan, G. Bhagavannarayana, N. Vijayan and R. Gopalakrishnan, J. Cryst. Growth, 306, 102 (2007); https://doi.org/10.1016/j.jcrysgro.2007.03.036. 